\title{
Blockchain Technologies in Healthcare Institutions: Focus on Security and Effective Cooperation with the Government
}

Submitted 20/08/19, 1st revision 18/09/19, 2nd revision 20/10/19, accepted 20/11/19

\author{
Yu.V. Przhedetskiy ${ }^{1}$, N.V. Przhedetskaya ${ }^{2}$, \\ K.V. Borzenko ${ }^{3}$, V.A. Bondarenko ${ }^{4}$
}

\begin{abstract}
:
Purpose: This article considers the relevance of healthcare modernization processes in Russia in terms of marketing activities activation, public-private partnerships intensification.

Design/Methodology/Approach: The problem of ensuring security when government and healthcare institutions interact by means of blockchain technologies is under-explored and requires further research and investigation. Therefore, methods of induction, deduction, problem, system and logical analysis along with the economic process and system modelling method combined with the formalization method are used in this article.

Findings: A mechanism for effective ensuring the safety of interaction between the government and healthcare institutions using blockchain technologies in the course of conducting financial flows and operational information exchange in modern Russia is proposed.

Practical Implications: The proposed mechanism for effective ensuring of security in terms of interaction between the government and the healthcare institution by means of blockchain technologies in modern Russia effectively ensures the security of interaction between the government and healthcare institutions .

Originality/Value: Authors' findings could be introduced into the healthcare industry.
\end{abstract}

Keywords: Blockchain technology, healthcare, development, electronic exchange, cooperation, security.

JEL Code: P36.

Paper type: Research note: Blockchain Technologies in Health.

\footnotetext{
${ }^{1}$ Head of the Department of Reconstructive Plastic Surgery, Rostov Research Cancer Institute, Rostov-on-Don, nvpr@bk.ru

${ }^{2}$ Professor of the Department of Economic Theory, Rostov State University of Economics, Rostov-on-Don,nvpr@bk.ru

${ }^{3}$ Assistant of the Department of Economics Theory, Rostov State University of Economics, Rostov-on-Don, $\underline{\text { _c cherry@mail.ru }}$

${ }^{4}$ Head of the Department of Marketing and Advertising, Rostov State University of Economics, Rostov-on-Don, b14v@yandex.ru
} 


\section{Introduction}

The focus on the development of social policy fully manifests itself in the framework of the general strategy for improving the national economy. In turn, the healthcare sector has great social significance, because the quality of life of the population and the potential for healing the nation depend on the volume and level of medical services provided and their accessibility. In addition, healthcare as a component of the service sector is a highly efficient industry, since along with solving the task of improving the nation it involves minimal consumption of natural resources and practically does not bear anthropogenic pressure on the environment.

It should be also noted that certain segments of the healthcare sector are among the high-tech sectors of the national economy. The intensity of building up their work contributes to the innovative development of the socio-economic system and its competitiveness. For this reason, modernization initiatives in the healthcare sector are relevant and are of some interest not only from a social, but also from an economic point of view.

According to the Draft Health Development Strategy of the Russian Federation for the period up to 2025 prepared by the Ministry of Health of the Russian Federation in 2017, the pivotal role is given to the state in its successful functioning in modern Russia, as well as the need to strengthen the interaction of the state and healthcare institutions for its modernization and increase in the overall efficiency along with general safety (Ministry of Health of the Russian Federation, 2017).

To date, the security problem is a serious barrier to the modernization of the healthcare sector in modern Russia and its effective functioning, which does not allow establishing a systematic interaction between the government and healthcare institutions. It seems that new technologies can help mitigate this problem. In this particular situation, blockchain technology is of interest (Albekov et al., 2017; Vovchenko et al., 2017).

In this connection, the study and identification of the main current and future areas of interaction between the government and healthcare institutions, the determination of possible problems in the framework of the focus on security and the development of a mechanism to ensure the security of interaction between the government and healthcare institutions, their effective functioning using blockchain technologies as applied to the current situation in the national economic system are of particular interest.

\section{Materials and Methods}

It is possible to determine two prospective directions of healthcare sphere modernization in modern Russia in the framework of theorists' and experts' works, both of them are connected with the engagement of marketing tools: 1) direct 
extension of the marketing activeness of healthcare institutions (Bagdasaryan, 2015; Mikhel and Gubina, 2014; Muzalevskaya, 2015; Przhedetskiy et al., 2017) and 2) establishment of a system of public and private partnership in the healthcare sphere, also presuming basis on marketing principles (Andreeva et al., 2014; Ganeev, 2014; Gladkov, 2016; Grachov and Shebasheva, 2016; Zherdev, 2015; Piskunov and Chevtaeva, 2015; Rozhkova and Kasenko, 2015; Przhedetskiy et al., 2017; Shcherbakova, 2015). Despite the fact that these directions are very prospective, they insufficiently reveal the potential of interaction between the government and healthcare institutions and prospects for its implementation to reach healthcare sphere modernization, especially in the framework of the focus on combining the effectiveness and security.

\section{Findings}

Currently, the government in Russia regulates a healthcare sphere in different ways, defining and influencing its key components, such as medical insurance, service quality standards, licensing of healthcare institutions operating, as well as providing and maintaining infrastructural support of entrepreneurship in the healthcare sphere.

The government performs a variety of roles in the healthcare sphere, being a consumer of services, a customer, an analyst, a planner, an employer, as well as the consumer of information and fundamentals of technical support at the same time. The state regulation of the healthcare sphere in modern Russia is based on the following principles reflecting key features of high effectiveness of this sphere:

- actions of the government are aimed at ensuring an access to covering basic medical services necessary to everyone for sustaining health of the state;

- the government aims at receiving medical services at an accessible, reasonable price by everyone, and these services should be safe, oriented to the patient and mutually coordinated;

- the state facilitates the development and improvement of the infrastructure in the healthcare sphere to ensure an access to all medical services necessary to each society individual.

Implementation of these principles in practice is a very complicated task. Its solving initiates the modernization process in the healthcare sphere of modern Russia. The traditional practice of the state monitoring, public procurement and providing all necessary medical services by public healthcare institutions begins to gradually shift to the accent on long-term and mutually beneficial partner relationships between public and private sectors for the most flexible response to the growing and modifying needs of the population.

The government also aims at serving a catalyst for changes for the better in the private sector of the healthcare sphere by means of simplifying administrative procedures and improving the business climate in the country. New information and communication 
technologies provided the government with the tools for successful transformation of the healthcare sphere. The reduction of costs for technologies and the Internet involving electronic communication in recent years have sharply extended opportunities of the government.

There are two major directions of e-interaction between the government and healthcare institutions which are feasible: information exchange and financial insurance, each of them characterized by the group of problems in terms of ensuring security resulted from electronic form of data transfer.

The first direction of interaction between the government and healthcare institutions is related to their information exchange. At present, information exchange in Russia is limited by the collection of statistical information in the healthcare sphere by the government. Data of corporate reporting of healthcare institutions is used by the government to assess effectiveness of their functioning, as well as for the purpose of monitoring of the general situation in the healthcare sphere, including:

- defining medical services in the highest demand;

- analysis of the sufficiency of infrastructural ensuring of the healthcare sphere;

- ratio between public and private healthcare institutions;

- considering opinions of patients on the functioning of healthcare institutions, etc.

A problem of ensuring security in interaction between the state and healthcare institutions is revealed in the framework of indicated operations. It is related to the unreliability of the Internet connection used, when transferring corporate reporting by healthcare institutions in the electronic way. The failure of the Internet connection can lead to inability to upload the data in the All-Russian statistical system and the bias of the results of statistical reporting in the healthcare sphere, overall, and effectiveness of certain institutions functioning. Elaboration of the state policy in the sphere of regulating the healthcare sphere based on incomplete, uncertain or invalid information, is initially hardly efficient, since incorrect administrative decisions are likely to be taken. These incorrect decisions would hamper its development rather than facilitate the growth of the healthcare sphere and compliance with the declared state regulation principles.

The perspective aspect of extending the information exchange between the government and healthcare institutions is creating the All-Russian electronic medical information data base, which would contain detailed information about all patients, their asking for medical assistance and using it. It will allow patients to apply for medical services to any institution convenient for them, both private and public medical services, and get medical services of highest quality, since medical workers will have all the necessary information for choosing an optimal treatment course. In this case, the problem of security in terms of interaction between the government and the healthcare institution is related not only to the imperfect Internet connection system, but also to the high probability of the misrepresentation and theft of 
confidential information about patients by cybercriminals. That is why this problem being unsolved becomes a major barrier to create the All-Russian electronic medical information data base (Polyakova et al., 2019; Belikova et al., 2019).

The second indicated direction of interaction between the government and the healthcare institution is financial security. At present, the financial insurance of healthcare institutions in Russia includes providing state donations and subsidies to healthcare institutions, as well as financing of public healthcare institutions functioning and payment of the public order in the healthcare sphere. Taking into account the immense scale of this financing defined by the strategic significance of the healthcare sphere for national economy, the state financial healthcare insurance also faces the problem of security in terms of the interaction between the government and the healthcare institution caused by the high attractiveness of the possible theft of finances for cybercriminals.

It is feasible to use blockchain technologies in both directions as a perspective solution of indicated problems of ensuring security in terms of interaction between the government and healthcare institutions (Nosov, 2017). These technologies, as a rule, are processes of data transfer (including the information and financial exchange) through an uninterrupted chain of interrelated blocks containing data.

This recommendation is explained by the fact that the interaction of the government and healthcare organizations in modern Russia is organized in accordance with the principle of the set of separate blocks. However, application of the traditional technology of data collection and storage, which entails a common server with the only data base, causes high vulnerability of data and the problem of security. In contrast to the vulnerability, advantages of using blockchain technologies for interaction between the government and the healthcare institution are as follows:

- the simplicity of information control by all stakeholders: all healthcare institutions can have access to the common database, but not only the government;

- sustainability of the data system to errors and its inviolability: digital data are expanded everywhere, but cannot be copied, and only a limited data block undergoes changes, this healthcare institution having access to it;

- constant update of the data system and sustaining it in the relevant state: when uploading new data, the system is automatically updated without the participation of the healthcare institution which uploaded it;

- transparence and control of the data system: it is easy to track the data source uploaded in the common system, what let's prevent cyber-attacks in the healthcare data systems.

The proposed mechanism for effective ensuring of security in terms of interaction between the government and the healthcare institution by means of blockchain technologies in modern Russia is introduced in Figure 1. 
Figure 1. Mechanism of effective security insurance in terms of interaction between the government and the healthcare institution by means of blockchain technologies in modern Russia

Objective: effective security insurance in terms of interaction between the government ans healthcare institutions

Tool for goal achievement: organization of electronic interaction between the state and healthcare institutions using blockchain technology

Mechanism for electronic interaction between the government and healthcare institutions using blockchain technology:

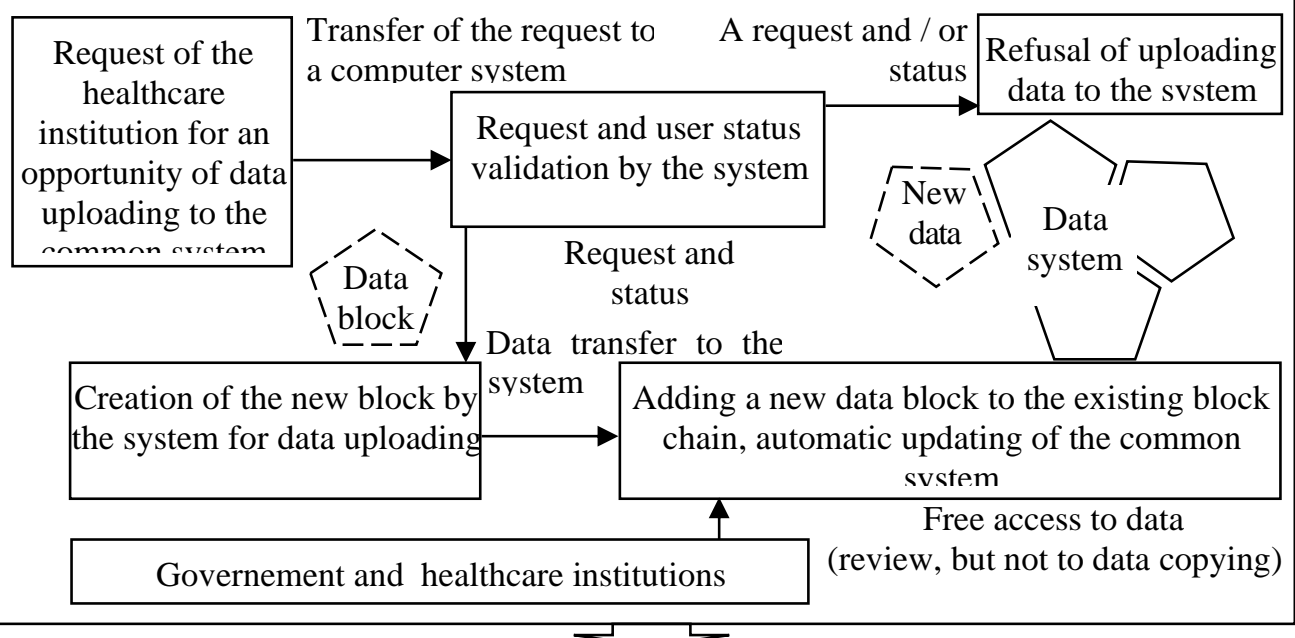

Outcome: simplicity of information control by all stakeholders, data system sustainability to errors and its inviolability, constant updating of data system and its maintenance upto-date, transparency and accountability of the data system

It is worth explaining that to define the most significant process and substantial characteristics of territorial marketing it is feasible to make the subjective assessment of audiences by the criteria of their belonging: inside the territory or outside it. It is feasible because audiences localized in the territory, as a rule, connect interest and fate in the long-term with this territorial entity; while external players focus on making a profit by developing their interests beyond its borders. In this case, when establishing contact with external audiences, it is necessary to find the reasonable one.

\section{Discussion}

The proposed mechanism of electronic interaction between the state and healthcare organizations using blockchain technologies (Figure 1) is characterized by increased reliability and security. First, the healthcare organization sends a request for the ability to upload data to the common system. Then, the request is transmitted to the computer 
network, and the request and user status are validated. If the request and / or status is not confirmed, the request is denied, and if confirmed, a new block is created to load the data by the user. Data is transferred to the common system and added to the existing block chain; the common system is automatically updated. The state and healthcare organizations have free access to data (to data viewing, but not copying). At the same time, the possibility of full protection of financial transactions and the necessary freedom of information exchange between the state and health organizations in their constant interaction is achieved.

\section{Conclusion}

Summarizing the above, it should be noted that currently there is an active electronic interaction between the government and healthcare institutions in Russia in the direction of information exchange and financial support, which will only expand in the future, and therefore the problem of ensuring the security of this interaction will intensify.

The use of blockchain technologies allows solving this problem and effectively ensuring the security of interaction between the government and healthcare institutions by increasing the degree of data protection and limiting the ability of users to use them.

\section{References:}

Albekov, U.A., Vovchenko, N., Andreeva, G., Vladimirovna, O. and Sichev, R.A. 2017. Block Chain and Financial Controlling in the System of Technological Provision of Large Corporations. European Research Studies Journal, 20(3B), 3-12.

Andreeva, O.V., Saitgareeva, A.A., Volkova, O.A. 2014. Public and private partnership in healthcare. Public health and healthcare, 4, 61-68.

Bagdasaryan, S.L. 2015. Methodological aspects of forming an effective marketing mechanism in the healthcare system. Management of economic systems, 4(76), 58.

Belikova K.M., Badaeva, N.V., Akhmadova, M.A. 2019. Economization of Information and Scientific Data: A Common Approach. International Journal of Economics and Business Administration, 7(1), 153-161.

Ganeev, A.M. 2015. Public and private partnerships as a source of financing for the healthcare system. Insurance, 7(268), 51-54.

Gladkov, K.V. 2016. Public-private partnerships as a source of competence of a private partner's competence in healthcare. Modern problems of science and education, 2, 125.

Grachov, M.M., Shebasheva, Ye.V. 2014. Public and private partnership: history and development prospects in the healthcare sector. Innovative management and law technologies, 3(10), 131-135.

Mikhel, Yu.V., Gubina, D.V. 2014. Marketing as an integral function of management in healthcare. Economics and Society, 2-3(11), 456-459.

Ministry of Health of the Russian Federation. 2017. Draft Health Development Strategy of the Russian Federation for the period until 2025. Available at: https://www.rosminzdrav.ru/ministry/61/22/stranitsa-979/strategiya-razvitiyazdravoohraneniya-rossiyskoy-federatsii.

Muzalevskaya, A.A. 2015. Marketing in the activities of a healthcare institution. Vestnik OrelGIET, 3(33), 63-66. 
Nosov, N. 2017. Blockchain and Medicine. Available at: http://www.iksmedia.ru/articles/ 5456962-Blokchejn-i-medicina.html.

Piskunov, S.V., Chevtaeva, N.G. 2015. Public and private partnership in healthcare management. Management Issues, 3(15), 38-48.

Polyakova, A.G., Loginov, M.P., Serebrennikova, A.I., Thalassinos, E.I. 2019. Design of a socio-economic processes monitoring system based on network analysis and big data. International Journal of Economics and Business Administration, 7(1), 130-139.

Przhedetskiy, Yu.V., Przhedetskaya, N.V., Borzenko, K.V. 2017. Relevant directions of marketing development of healthcare organizations using public and private partnerships in modern Russia. Vestnik of Tula State University, Economic and Legal Sciences, 1(1), 124-132.

Przhedetskiy, Yu.V., Przhedetskaya, N.V., Przhedetskaya V.Yu., Bondarenko, V.A. 2017. The role of media education in training medical personnel and improving the provision of medical services. Media Education, 4, 26-36.

Rozhkova, Ye.V., Kasenko, O.V. 2015. Public and private partnership: notion, meaning, main directions of implementation in the field of healthcare. Conference proceedings of the Research and Development Center, Sociosphere, 19, 7-9.

Shcherbakova, K.S. 2015. Public and private partnership in healthcare. Economy, Business, Banks, 1, 94-102.

Vovchenko, G.N., Andreeva, V.A., Orobinskiy, S.A. and Filippov, M.Y. 2017. Competitive Advantages of Financial Transactions on the Basis of the Blockchain Technology in Digital Economy. European Research Studies Journal, 20(3B), 193-212.

Zherdev, R.A. 2015. Public and private partnership as a driver for the development of domestic healthcare. Russian entrepreneurship, 16(18), 3125-3138. 